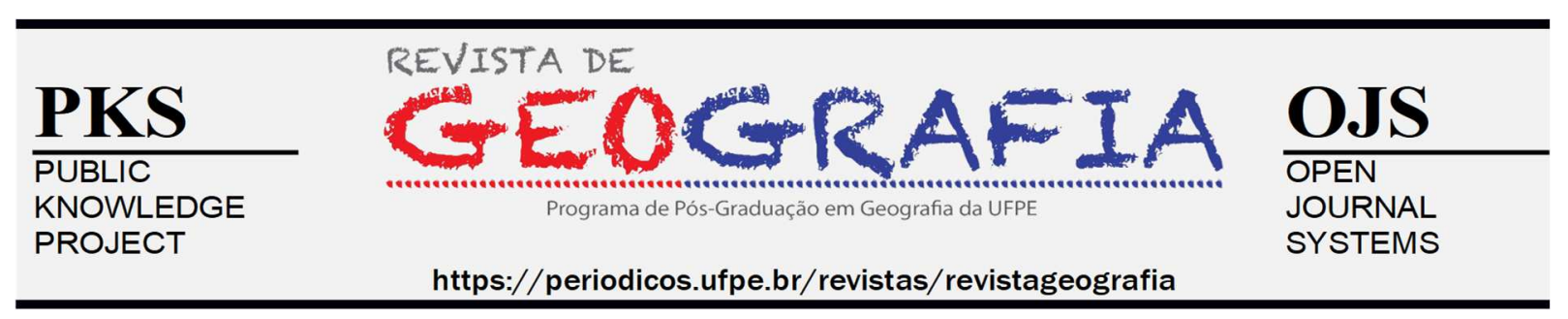

\title{
ESTILOS FLUVIAIS DO ALTO CURSO DO RIO PIRANHAS, AMBIENTE SEMIÁRIDO (PB)
}

\author{
Jeferson Mauricio Rodrigues ${ }^{1}$, Jonas Otaviano Praça de Souza ${ }^{2}$ \\ ${ }^{1}$ Doutorando em Geografia pelo Programa de Pós-Graduação em Geografia da Universidade Federal da Paraíba \\ (PPGG-UFPB). E-mail: jefersonmrgeo@gmail.com, Orcid: https://orcid.org/0000-0003-0117-1808. \\ 2 Doutor em Geografia e professor adjunto do Departamento de Geografia da Universidade Federal da Paraíba. \\ E-mail: jonas.souza@academico.ufpb.br, Orcid: https://orcid.org/0000-0002-1405-0944.
}

Artigo recebido em 26/07/2020 e aceito em 28/02/2021

\begin{abstract}
RESUMO
O semiárido brasileiro apresenta déficit hídrico durante a maior parte do ano devido aos valores de evaporação superarem os de precipitação. Entretanto, os canais das terras secas são os principais esculturadores de sua superfície e fornecedores de água para a população do perímetro seco mesmo apresentando escoamento em pulsos, ou seja, esporádicos. Nessa perspectiva, diversos estudos surgem através de adaptações para gerar um entendimento da realidade fluvial semiárida do Nordeste brasileiro. Todavia, a compreensão do sistema fluvial semiárido está além de adaptações teórico-metodológicas. Desta maneira, optou-se pela aplicação da estrutura de estilos fluviais, que é uma classificação aberta e que permite aplicação em diversos tipos de clima, já que é baseada numa perspectiva morfológica, permitindo proporcionar compreensão acerca dos canais fluviais na bacia do alto curso do rio Piranhas - PB. Foram identificados e caracterizados 6 estilos fluviais a partir de critérios definidos na etapa dois da estrutura de estilos fluviais, onde juntos em sua totalidade proporcionaram interpretação e compreensão da dinâmica fluvial semiárida na bacia do Alto Curso do Rio Piranhas.
\end{abstract}

Palavras-chave: Semiárido; Bacia Hidrográfica; Estilos Fluviais.

\section{RIVER STYLES OF THE HIGH COURSE OF THE PIRANHAS RIVER, ENVIRONMENT SEMIÁRID (PB)}

\begin{abstract}
The Brazilian semiarid region has a water deficit during most of the year due to the evaporation values exceeding those of precipitation. However, the dry land channels are the main sculptors of its surface and water suppliers for the population of the dry perimeter, even with flow in pulses, that is, sporadic. In this perspective, several studies emerge through adaptations to generate an understanding of the semi-arid fluvial reality of the Brazilian Northeast. However, understanding the semi-arid river system is beyond theoretical and methodological adaptations. In this way, it was decided to apply the structure of fluvial styles, which is an open classification and allows application in different types of climate, since it is based on a morphological perspective, allowing to provide understanding about the fluvial channels in the upper course basin Piranhas river - PB. Six river styles were identified and characterized based on criteria defined in step two of the structure of river styles, where together in their entirety they provided interpretation and understanding of semi-arid river dynamics in the Upper Course of the Piranhas River basin.
\end{abstract}

Keywords: Semiarid; Hydrographic Basin; River Styles.

Rodrigues e Souza, 2021

ISSN 0104-5490 


\section{INTRODUÇÃO}

As terras secas são caracterizadas por serem áreas de pouca chuva, no entanto, os detalhes de sua superfície são atribuídos à atuação dos sistemas fluviais. Logo, compreender as paisagens de terras secas é entender os processos e formas fluviais (GRAFF, 2011). Além disso, a produção do conhecimento sobre dinâmica e morfologia de sistemas fluviais áridos e semiáridos está entre as principais prioridades de pesquisa em terras secas e que ajudará a desenvolver uma base teórica sólida sobre os canais fluviais dessas regiões (TOOTH, 2000).

O comportamento normal de canais fluviais de terras secas é quando eles estão secos (TOOTH, 2000). Desta maneira, a dinâmica fluvial semiárida é composta por dois tipos predominantes de escoamentos superficiais canalizados, que são canais efêmeros e intermitentes, os quais apresentam descontinuidade no fluxo em algum momento no tempo e no espaço, onde o canal intermitente só apresenta fluxo durante o período chuvoso (DATRY et al, 2017), e os canais efêmeros apresentam escoamento superficial de curta duração que varia de horas a poucos dias durante ou logo após o evento de chuva (SUTFIN, 2014).

Rosgen (1994), afirma que sistemas de classificação fluvial são metas para indivíduos que trabalham com rios, servindo para compreender os seus processos que possuem um grau de complexidade elevado sobre um conjunto de variáveis inter-relacionadas que determinam a morfologia (dimensão, padrão e perfil) de um canal.

A proposta teórico-metodológica de River Styles (Estilos Fluviais) criada pelos pesquisadores australianos Brierley e Fryirs, junto à agência australiana de conservação da água é um tipo de classificação de canal com base nos aspectos morfológicos de um rio. Dessa forma, eles utilizam na sua classificação quatro escalas interligadas: bacias hidrográficas, unidades de paisagem, canal e unidades geomórficas (BRIERLEY; FRYIRS, 2005). Essa abordagem disseca efetivamente uma bacia, caracterizando estilos de rios para diferentes unidades de paisagem. Já os estilos são definidos a partir de analises em termos de confinamento de vale, visão em planta e o conjunto das unidades geomórficas.

Diferentes pesquisas foram feitas com essa proposta teórico-metodológica para o ambiente semiárido no Brasil, como é o exemplo de Souza (2014), Maia (2016), Santos (2017) e Oliveira (2018).

Dado o exposto, o presente trabalho tem como objetivo definir os estilos fluviais do alto curso do rio Piranhas, no Sertão do Estado da Paraíba. 


\section{METODOLOGIA}

\section{Caracterização da área}

Este trabalho tem como área de análise o alto curso do rio Piranhas, localizado no Sertão paraibano e ocupando uma área de 35 Municípios, que dentre os principais estão: Cajazeiras, Souza e Pombal (Figura 1). Este canal apresenta característica de vazão intermitente por apresentar vazão apenas durante a estação chuvosa da bacia.

\section{FIGURA 1 - MAPA DE LOCALIZAÇÃO DO ALTO CURSO DO RIO PIRANHAS}

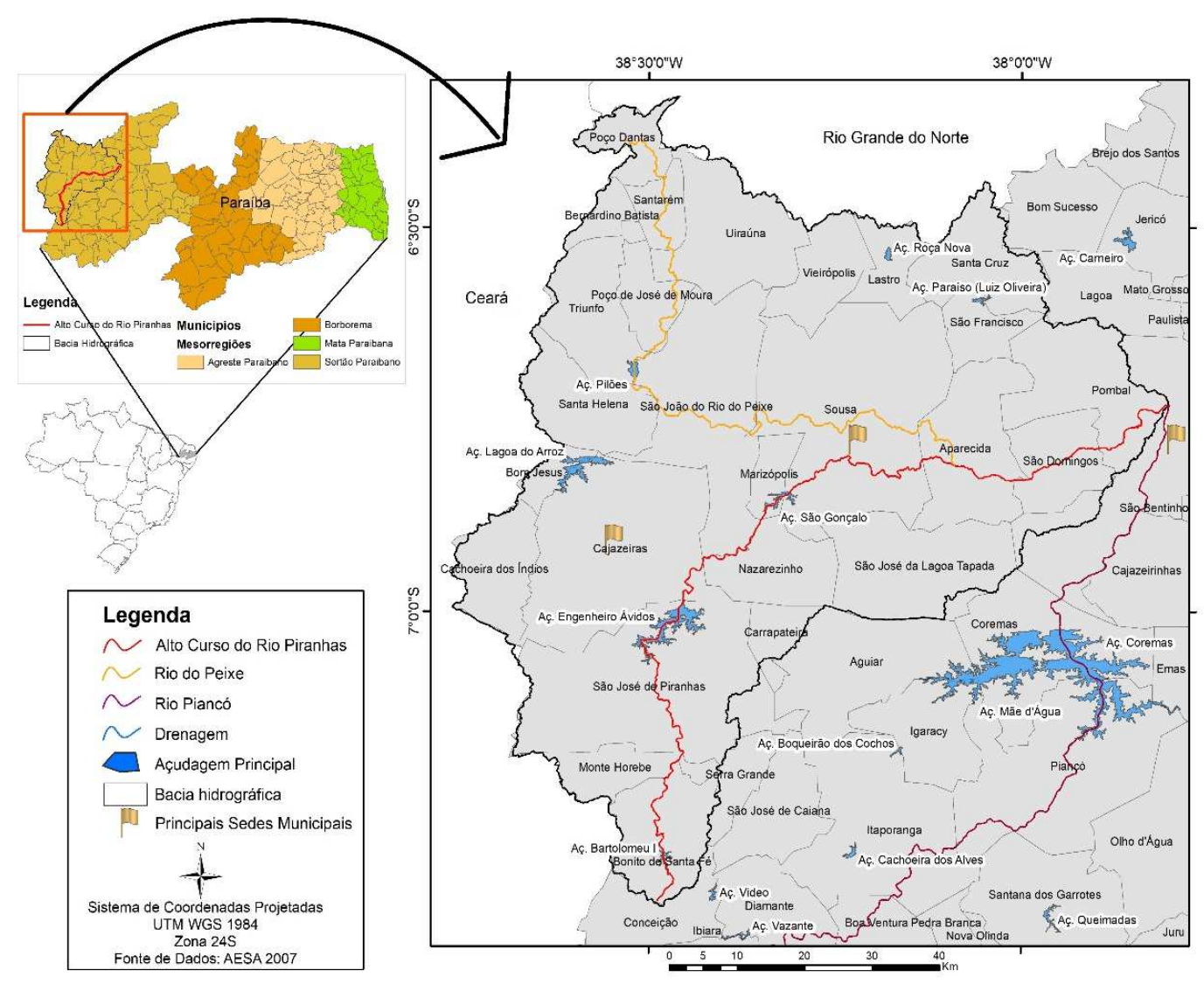

Fonte: Autor, 2019

A área da bacia do alto curso do rio Piranhas possui características físicas semelhantes à maioria das áreas do semiárido nordestino. A maioria da área da bacia está em torno de 170 a $500 \mathrm{~m}$ de altitude e apresentam topografia que varia majoritariamente de plano a suave ondulado (Figura 2), onde tais compartimentos deprimidos oriundos de denudação e circundesnundação em torno do planalto da Borborema faz com que essas áreas deprimidas de relevo suave e baixo constituam parte das principais áreas semiáridas do interior do Nordeste 
brasileiro (MAIA, et al., 2010) e ocorrem principalmente sobre as litologias cristalinas pertencentes à subprovíncia estrutural Rio Grande do Norte, esta última sendo parte da Província Estrutural Borborema (GONÇALVES, 2009).

De modo geral, as áreas mais elevadas acima de $500 \mathrm{~m}$ de altitude possuem substrato de rochas intrusivas plutônicas paleoproterozóicas e de topo suave ondulado constituindo os Patamares Elevados de Dissecação (Figura 2).

FIGURA 2 - UNIDADES DE RELEVO DO ALTO CURSO DO RIO PIRANHAS.

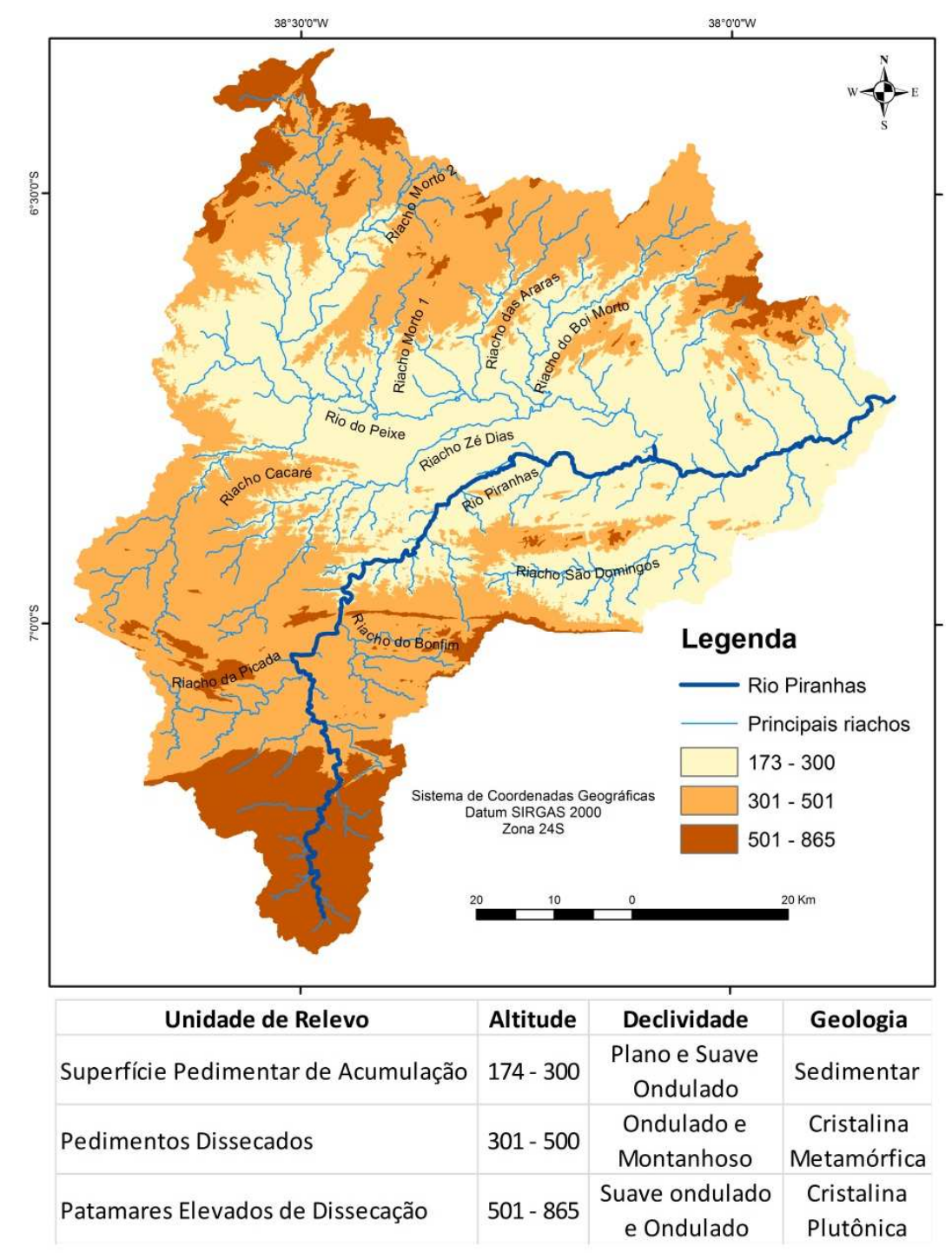

Fonte: Autor, 2020 
As áreas intermediárias, com altitudes variando de 300 a $500 \mathrm{~m}$ possuem substratos compostos por complexos metamórficos meso-neoproterozóicos e com amplas áreas íngremes, correspondentes às serras e inselbergs que ocorrem na bacia constituindo os Pedimentos Dissecados. As áreas abaixo de $300 \mathrm{~m}$ são constituídas por um substrato sedimentar relacionado a processos de subsidência a partir de reativações das zonas de cisalhamento durante o ciclo brasiliano, onde a principal fase do sistema de rifteamento ocorreu durante o Neocomiano-Barremiano, com desenvolvimento dos Rifts Valleys e extenso fraturamento da crosta superior, gerando a única bacia sedimentar intracratônica existente no Estado da Paraíba, que é a bacia sedimentar do rio do Peixe (NOGUEIRA; OLIVEIRA; CASTRO, 2004), com topografia aplainada e amplas áreas aluviais constituindo a Superfície Pedimentar de Acumulação.

O clima da bacia é típico do semiárido brasileiro, ocorrendo chuvas concentradas entre os meses de fevereiro e abril, correspondendo à quadra chuvosa da bacia, sendo gerados por sistemas climáticos como a ZCIT (RODRIGUES, 2020) e também, decorrentes dos VCAN's, sendo estes últimos circulações ciclônicas fechadas, onde o centro é mais frio que seu entorno, (VAREJÃO-SILVA, 2006), transformando energia potencial em cinética pelo movimento descendente no centro frio e ascendente na periferia (KOUSKY; GAN, 1981). Além de distribuição irregular temporalmente, as chuvas também são mal distribuídas espacialmente, onde os setores com altitude entre 300 e $500 \mathrm{~m}$ recebem as maiores taxas de precipitação da bacia (RODRIGUES, 2020).

\section{Procedimentos metodológicos}

Para definir estilos fluviais semiáridos, é necessário seguir algumas etapas, onde cada etapa apresenta alguns procedimentos conforme observado na Figura 3. Desta maneira, a Etapa 1 consiste na análise da bacia hidrográfica, tendo como foco a definição das unidades de relevo e os perfis longitudinais. As unidades de relevo foram definidas com base na homogeneidade de variáveis como topografia e geologia. Após a definição das unidades de relevo, foi feita uma análise do perfil longitudinal da bacia, que segundo Silva et al., (2016), o perfil longitudinal de um rio representa suas variações topográficas no que tange à altimetria e declividade e está intimamente ligado ao relevo. O perfil longitudinal foi elaborado através de dados de topografia trabalhados em ambiente SIG e plotados no Excel. 
FIGURA 3 - PROCEDIMENTOS NECESSÁRIOS PARA DEFINIR E INTERPRETAR O CARÁTER E COMPORTAMENTO DOS ESTILOS FLUVIAIS

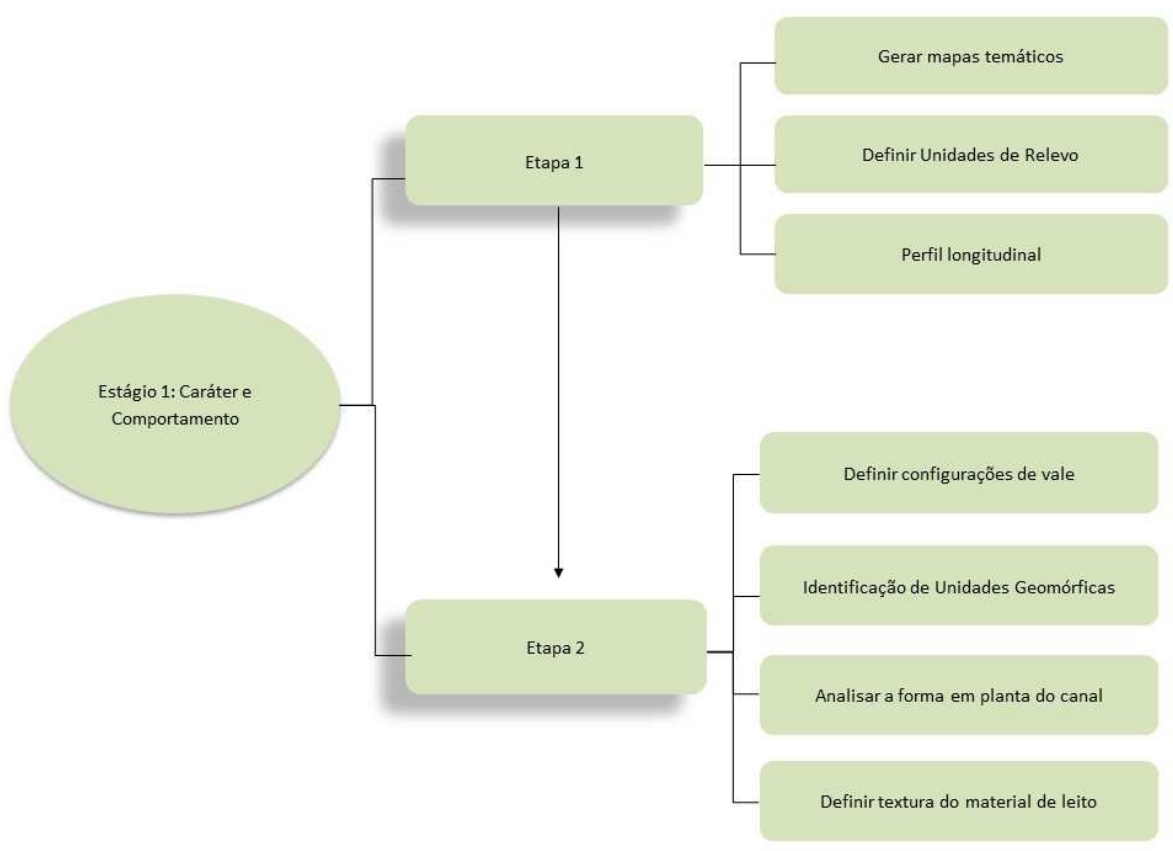

Fonte: Brierley e Fryirs, 2005

$\mathrm{Na}$ etapa dois foi possível definir e mapear os estilos de rio na bacia hidrográfica e é neste momento que a escala passa de bacia hidrográfica para canal fluvial. Para isso, foi necessário avaliar três variáveis do alto curso do rio Piranhas para definir os estilos, que foram: configuração de vale, unidades geomórficas e textura de material de leito (Quadro 1).

QUADRO 1 - VARIÁVEIS AVALIADAS PARA DETERMINAR A CONFIGURAÇÃO DO VALE

\begin{tabular}{|c|c|c|c|}
\hline CONFIGURAÇÃO DE & CONFIGURAÇÃO DE VALE & \multicolumn{2}{|c|}{ CONFIGURAÇÃO DE VALE NÃO - CONFINADO } \\
\hline $\begin{array}{l}(>90 \% \text { DE MARGEM } \\
\text { CONFINADA) }\end{array}$ & $\begin{array}{c}\text { (ENTRE } 10 \text { E } 90 \% \text { DE } \\
\text { CONFINAMENTO DE MARGEM) }\end{array}$ & \multicolumn{2}{|c|}{$(<10 \%$ DE CONFINAMENTO DE MARGEM) } \\
\hline $\begin{array}{c}\text { PRESENÇA/AUSÊNCIA } \\
\text { DE VÁRZEAS }\end{array}$ & $\begin{array}{c}\text { GRAU DE CONFINAMENTO } \\
\text { LATERAL E CONFIGURAÇÃO DO } \\
\text { VALE (RETO - IRREGULAR - } \\
\text { SINUOSO) }\end{array}$ & $\begin{array}{l}\text { AUSÊNCIA OU CANAIS } \\
\text { DESCONTÍNUOS }\end{array}$ & $\begin{array}{l}\text { PRESENÇA DE CANAIS } \\
\text { CONTÍNUOS }\end{array}$ \\
\hline $\begin{array}{c}\text { UNIDADES } \\
\text { GEOMÓRFICAS }\end{array}$ & FORMA EM PLANTA DO CANAL & $\begin{array}{c}\text { UNIDADES } \\
\text { GEOMÓRFICAS }\end{array}$ & FORMA EM PLANTA \\
\hline \multirow[t]{2}{*}{$\begin{array}{l}\text { TEXTURA DE MATERIAL } \\
\text { DE LEITO }\end{array}$} & UNIDADES GEOMÓRFICAS & $\begin{array}{l}\text { TEXTURA DE MATERIAL } \\
\text { DE SUPERFÍCIE }\end{array}$ & $\begin{array}{l}\text { UNIDADES } \\
\text { GEOMÓRFICAS }\end{array}$ \\
\hline & $\begin{array}{l}\text { TEXTURA DE MATERIAL DE } \\
\text { LEITO }\end{array}$ & & $\begin{array}{l}\text { TEXTURA DE MATERIAL } \\
\text { DO LEITO }\end{array}$ \\
\hline
\end{tabular}

Fonte: Adaptado de Brierley e Fryirs, 2005.

A configuração de vale foi o ponto de entrada para definir os estilos de rio, e foi definida pelo grau de confinamento do canal, expressa pela presença/ausência de várzeas ao 
longo dos cursos fluviais. Assim, os canais podem ser confinados, parcialmente confinados e não confinados. Geralmente os canais confinados apresentam menos de $10 \%$ de planícies de inundação em ambas as margens do canal. Os parcialmente confinados apresentam entre $10 \%$ e $90 \%$ de planície de inundação em ambas as margens do canal, e dessa forma as planícies podem ser alternadas ou descontínuas ao longo do curso fluvial. Os não confinados apresentam menos de $10 \%$ de confinamento de margem, com planícies de inundação contínuas ao longo das margens e podem ter canais contínuos e canais descontínuos. Nessa perspectiva, para gerar informações sobre o confinamento de vale, foram identificadas as planícies de inundação através das imagens espaciais disponíveis no Google Earth Pró e confirmadas em campo. Também foi utilizada estação total em alguns locais do canal que permitiu identificar as variações topográficas numa perspectiva transversal, onde os pontos de coleta foram de uma margem à outra. Nesta etapa 2 o campo foi fundamental para coleta de dados, observação e análise da paisagem, tendo em vista as variações existentes em cada ponto definido em gabinete.

De acordo com Brierley e Fryirs (2005) as unidades geomórficas são ferramenta chave para interpretar o caráter e comportamento do canal, sendo o principal parâmetro interpretativo na estrutura de estilos de rio e os critérios utilizados foram: número de canais, sinuosidade, barras e ilhas. Para identificar número de canais, sinuosidade, barras e ilhas foram utilizadas as imagens de satélite mais recentes do Google Earth que permitiram visualizar a planta do canal.

A textura de material de leito foi determinada através da base de calibre dominante encontrado no leito fluvial. Assim, foram utilizados procedimentos de análise granulométrica em laboratório para definir o calibre do material sedimentar encontrado no leito dos sistemas fluviais. Assim, foram utilizadas 5 classes: Leito rochoso; Rocha (> $256 \mathrm{~mm})$; Cascalho (2 $256 \mathrm{~mm})$; Areia (0,0625 - $2 \mathrm{~mm})$; Silte e Argila $(<0,0625 \mathrm{~mm})$.

Após o alcance das etapas 1 e 2 do estágio 1 foi possível gerar um mapa geral de estilos fluviais para o alto curso do rio Piranhas. Posteriormente, foi possível analisar os estilos fluviais de acordo com a sua localização nas unidades de relevo no intuito de compreender a influência da variação de declividade, altimetria e geologia na condição dos estilos fluviais. 


\section{RESULTADOS E DISCUSSÕES}

Na etapa 1 da classificação de estilos fluviais foi necessária uma caracterização física da bacia hidrográfica do alto curso do rio Piranhas. Desta maneira, a bacia foi dividida em três unidades de relevo com base na geologia, declividade e altimetria, onde a homogeneidade predominante de cada variável funcionou como índice de classificação de unidade de relevo (Figura 4). De acordo com a figura 4, a bacia apresenta três grandes unidades de relevo em seu perímetro: (1) Patamares Elevados de Dissecação, (2) Pedimento Dissecado, (3) Superfície Aplainada de Agradação.

FIGURA 4 - MAPA DE UNIDADES DE RELEVO E PERFIL LONGITUDINAL DO ALTO CURSO DO RIO PIRANHAS

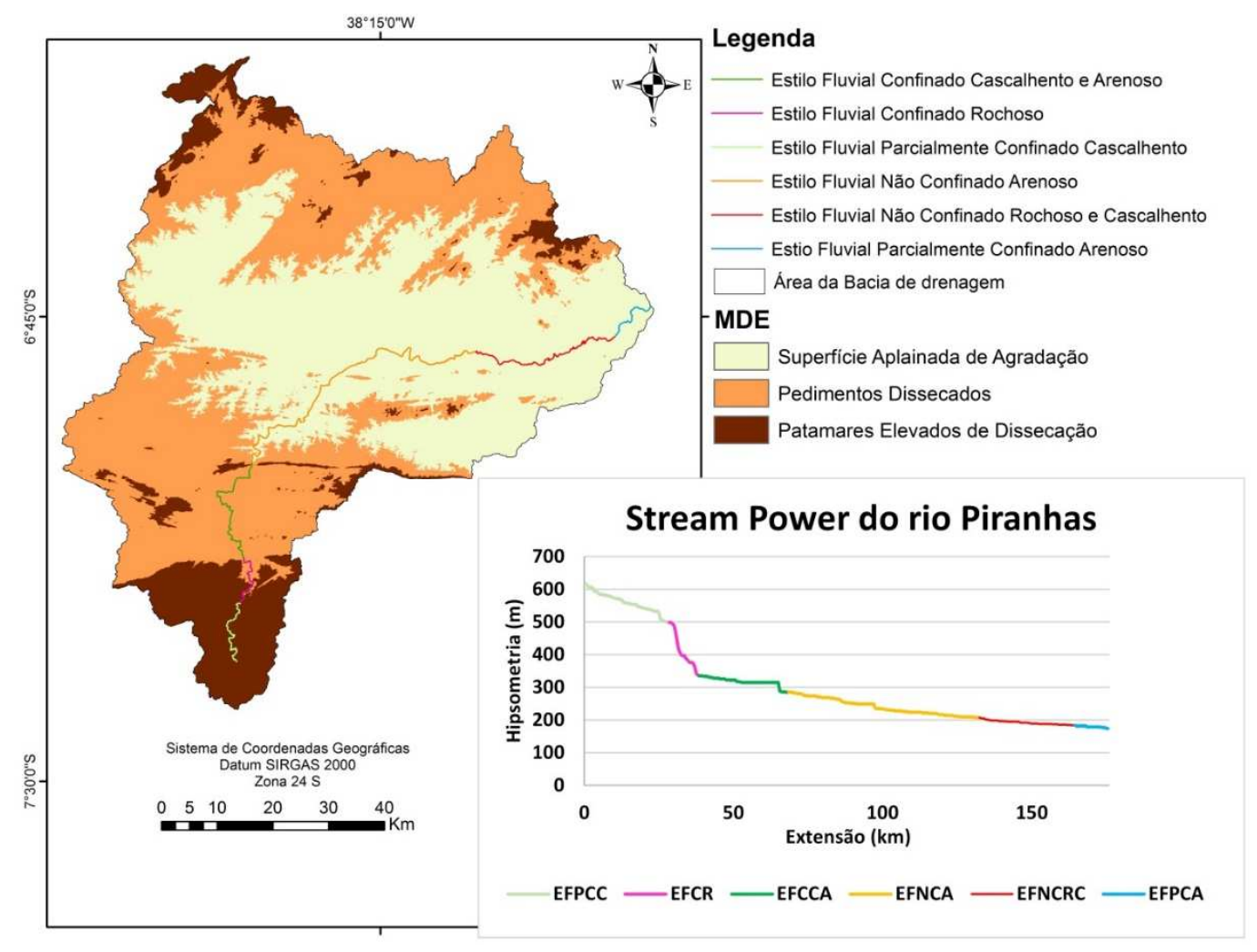

Fonte: Autor, 2019

Através da obtenção das informações acerca da bacia, foi possível chegar à definição de suas características gerais, e nesse contexto foram definidos 6 estilos fluviais com base nas variáveis de análise da etapa 2 da classificação de estilos (Figura 5). Observa-se na figura 5 que ocorrem 6 estilos fluviais na bacia, sendo dois confinados, dois parcialmente confinados e 
dois não confinados. Os estilos não confinados são os estilos mais extensos da bacia, variando de $55 \%$ da extensão total do alto curso do rio Piranhas.

FIGURA 5 - MATRIZ DE ESTILOS FLUVIAIS DO ALTO CURSO DO RIO PIRANHAS

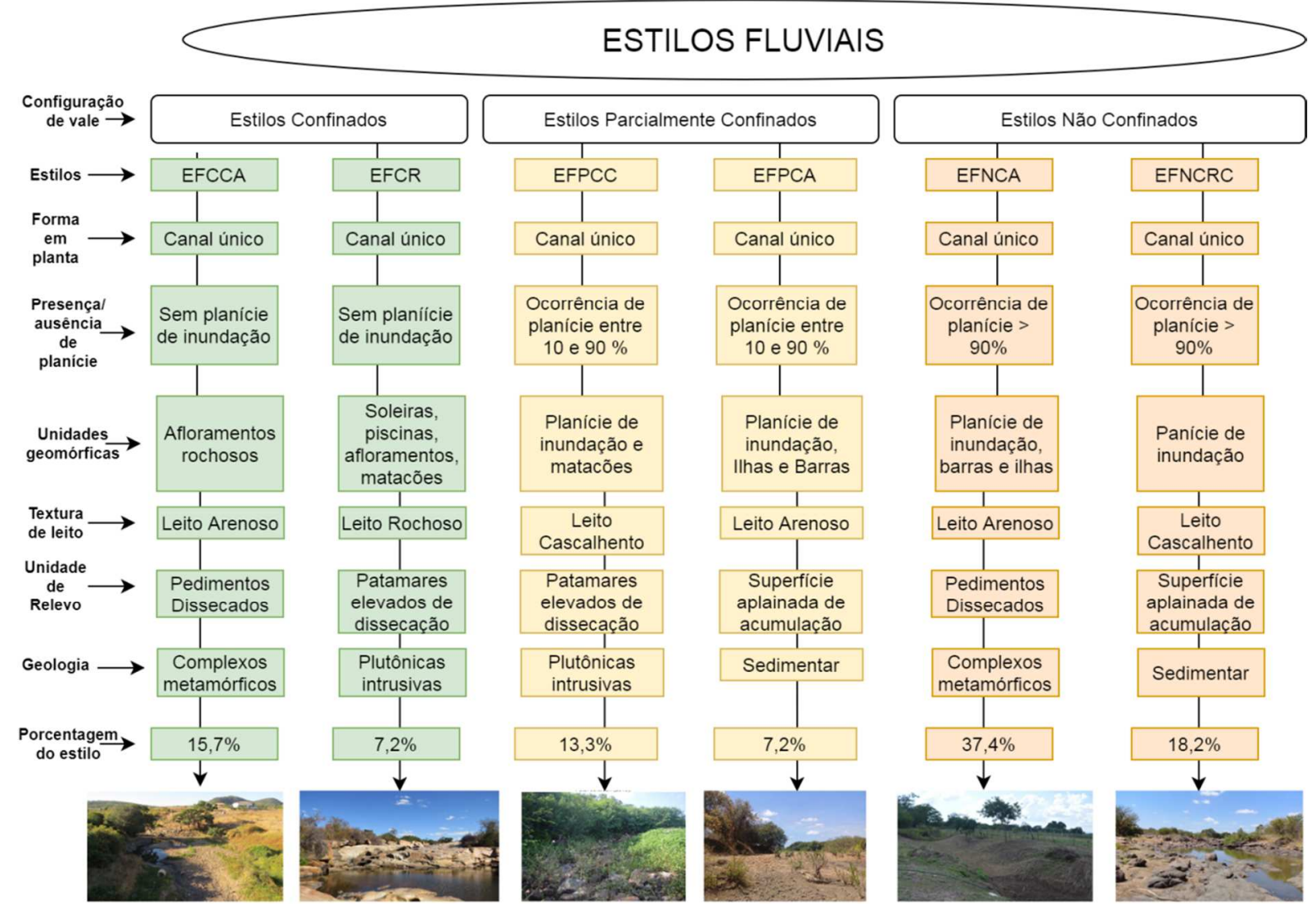

Fonte: Autoral, 2019

\section{Estilos Confinados}

A bacia hidrográfica do alto curso do rio Piranhas possui apenas dois estilos fluviais confinados. Estes correspondem aos trechos que escoam sobre o cristalino das cabeceiras de drenagem. Nessa perspectiva são canais que não apresentam planícies de inundação nas margens fluviais e sofrem influência do embasamento cristalino.

O Estilo Fluvial Confinado Rochoso (EFCR) está situado no contato entre as unidades geológicas Granitóides de Quimismo Indiscriminados e Santana dos Garrotes, onde ocorre uma ruptura de declive de $183 \mathrm{~m}$ de amplitude numa faixa de 13,5 km de extensão. Este atributo no sistema fluvial do EFCR condiciona uma morfologia de canal único com leito rochoso e assimétrico, e com a presença de unidades geomórficas como marmitas, matacões e 
corredeiras sob uma declividade de 1,3\%, sendo esse estilo o que apresenta maior declividade na bacia (Figura 6) e corresponde a 7,2\% de toda a extensão do rio Piranhas. Segundo Wohl e Merritt (2001), canais com altas declividades são capazes de gerar evolução vertical graças ao condicionamento aos processos erosivos, mas que podem apresentar um limite de evolução vertical dependendo das condições de resistência do leito, implicando geralmente em uma morfologia rochosa no leito fluvial. Este estilo está inserido em uma zona de contato entre as unidades de relevo Patamares Elevados de Dissecação e Pedimentos Dissecados que são separadas por uma linha de falha geológica transversal ao sentido do escoamento do rio Piranhas, e faz a drenagem de uma área de $296 \mathrm{~km}^{2}$. Nessa perspectiva, durante a estação seca o canal não apresenta indícios de deposição de material sedimentar, apenas algumas aglomerações de areia no sopé dos matacões que atuam como impedimentos naturais à passagem desse material. Todavia, na estação chuvosa, este trecho apresenta competência de transporte suficiente para transportar todo o material fino advindos das áreas de cabeceira da bacia.

\section{FIGURA 6 - ESTILO FLUVIAL CONFINADO ROCHOSO}
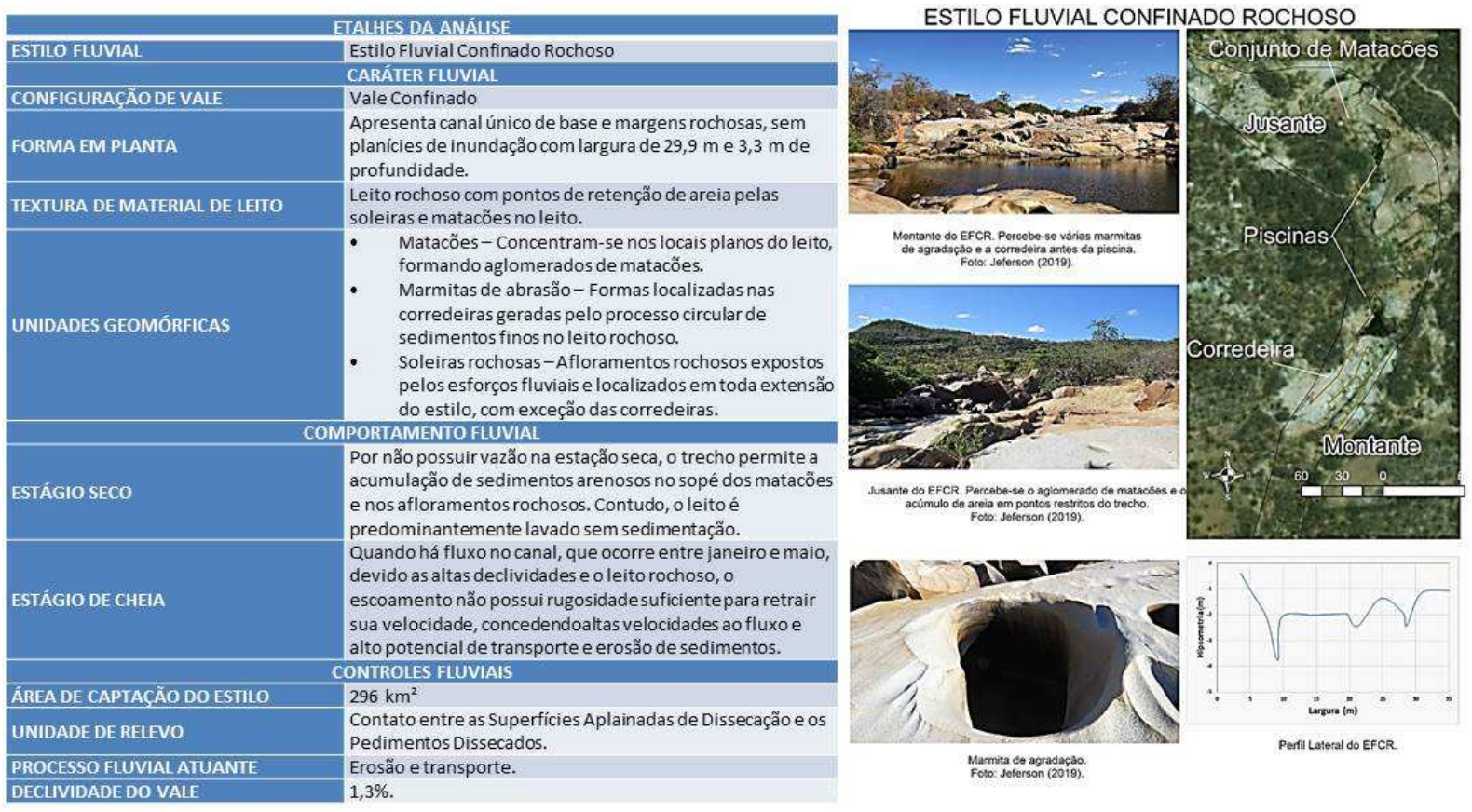

Fonte: Autor, 2020 
O Estilo Fluvial Confiando Cascalhento e Arenoso (EFCCA) está situado logo após o EFCR. Este estilo está situado inteiramente sobre a unidade de relevo Pedimentos Dissecados de substrato composto por rochas metamorfizadas. O que diferencia o EFCCA do EFCR é que existe uma diferença nos valores de declividade entre esses estilos, além das unidades geomórficas. Desta maneira, o Estilo Fluvial Confinado Cascalhento e Arenoso possui uma uma declividade de $1 \%$. Com isso, esse estilo é confinado na margem direita por controles litológicos e na margem esquerda por uma encosta. Também ocorrem maiores incidências de deposição de material sedimentar do tipo arenoso (Figura 7). Esse estilo faz a drenagem de uma área de $325 \mathrm{~km}^{2}$ e nele ocorrem processos simultâneos de transporte e deposição. Todavia, estes processos fluviais são mais nítidos de acordo com o período chuvoso. Nessa perspectiva, no período seco ocorre a predominância de sedimentação de material arenoso no leito, enquanto que na estação chuvosa o processo predominante é o de transporte de material fino.

\section{FIGURA 7 - ESTILO FLUVIAL CONFINADO CASCALHENTO E ARENOSO.}
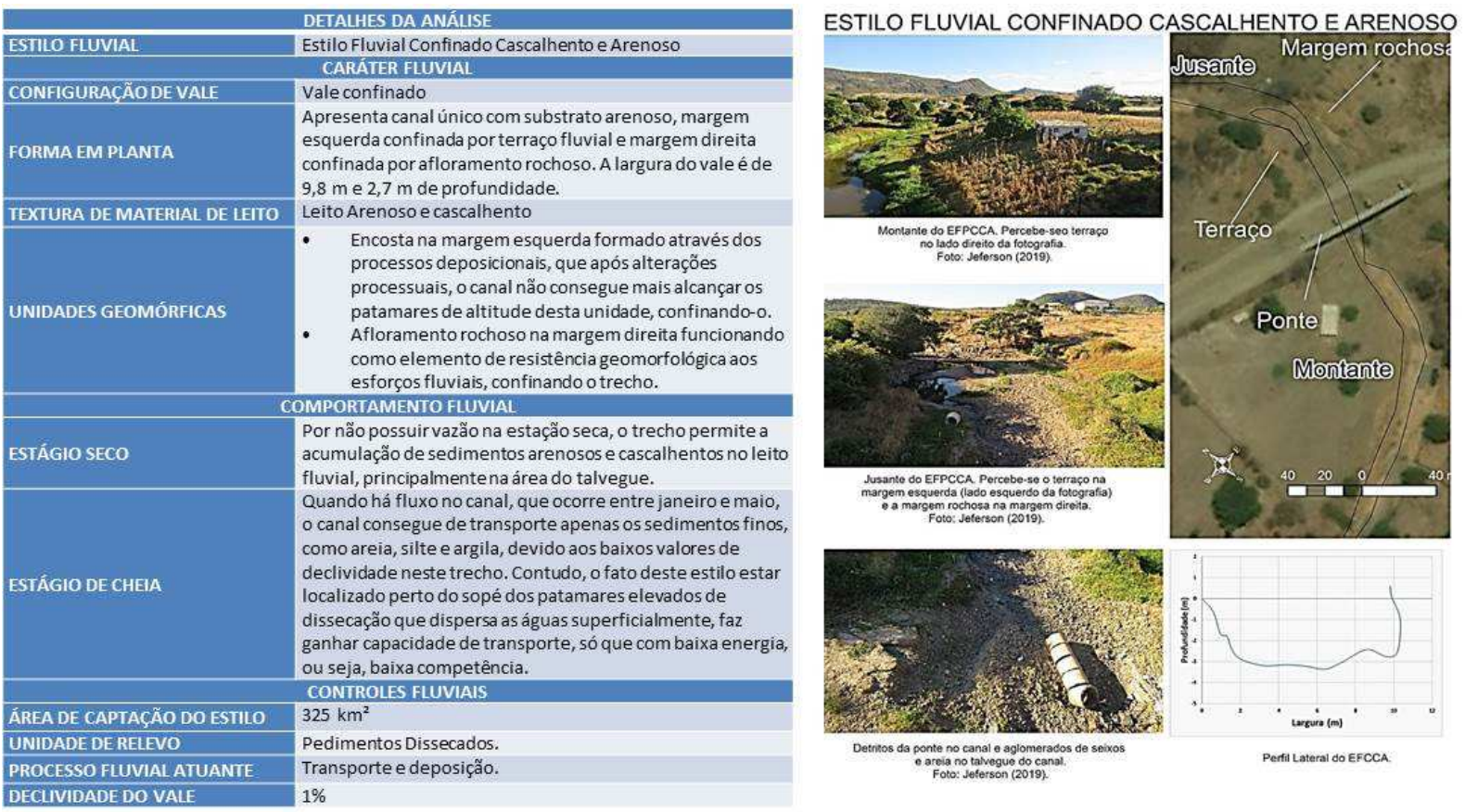

Fonte: Autoral., 2020

De modo geral, o Estilo Fluvial Confinado Cascalhento e Arenoso (EFCCA) está localizado logo após o Estilo Fluvial Confinado Rochoso (EFCR), e o que contribui para variação na forma e processos atuantes nestes estilos são os fatores geologia e declividade, pois enquanto o EFCR está situado sobre uma ruptura de declive associada ao contato entre 
duas unidades geológicas variando de rochas intrusivas plutônicas a complexos metamórficos que marcam os limites de duas unidades de relevo, o EFCCA situa-se sobre uma área majoritariamente aplainada de substrato metamórfico.

\section{Estilos Parcialmente Confinados}

A unidade de relevo Patamares Elevados de Dissecação está situada nas áreas de cabeceira de drenagem com as maiores cotas altimétricas da bacia, que variam de 500 a 861 $\mathrm{m}$, e com uma declividade que varia de suave ondulado a ondulado sobre geologia composta por corpos plutônicos intrusivos. Nessa perspectiva, é sobre esta unidade que ocorre o Estilo Fluvial Parcialmente Confinado Cascalhento (EFPCC), que apresenta entre $10 \%$ e 90\% a presença de planícies de inundação em uma de suas margens. Portanto, o substrato rochoso associado a baixas variações de declividade atribuem o caráter fluvial parcialmente confinado de leito cascalhento nesse estilo. Esse estilo fluvial apresenta canal único, planície de inundação contínua em uma das margens e a presença de matacões no ambiente fluvial, com a predominância de leito cascalhento (Figura 8).

\section{FIGURA 8 - ESTILO FLUVIAL PARCIALMENTE CONFINADO CASCALHENTO.}

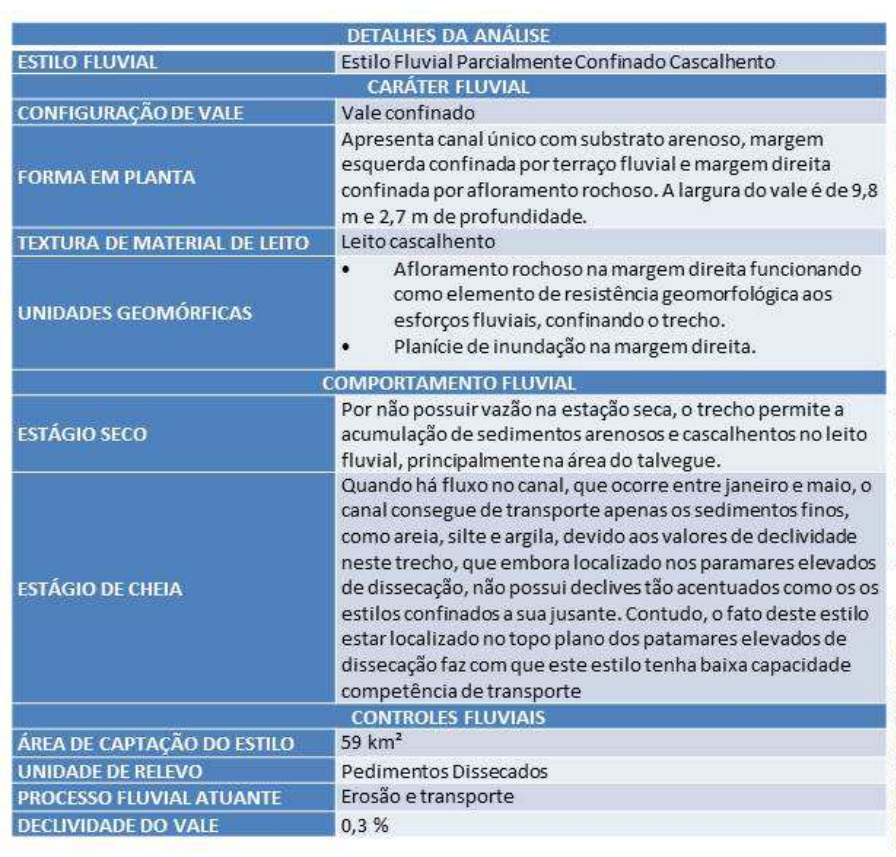

Fonte: Autor, 2020

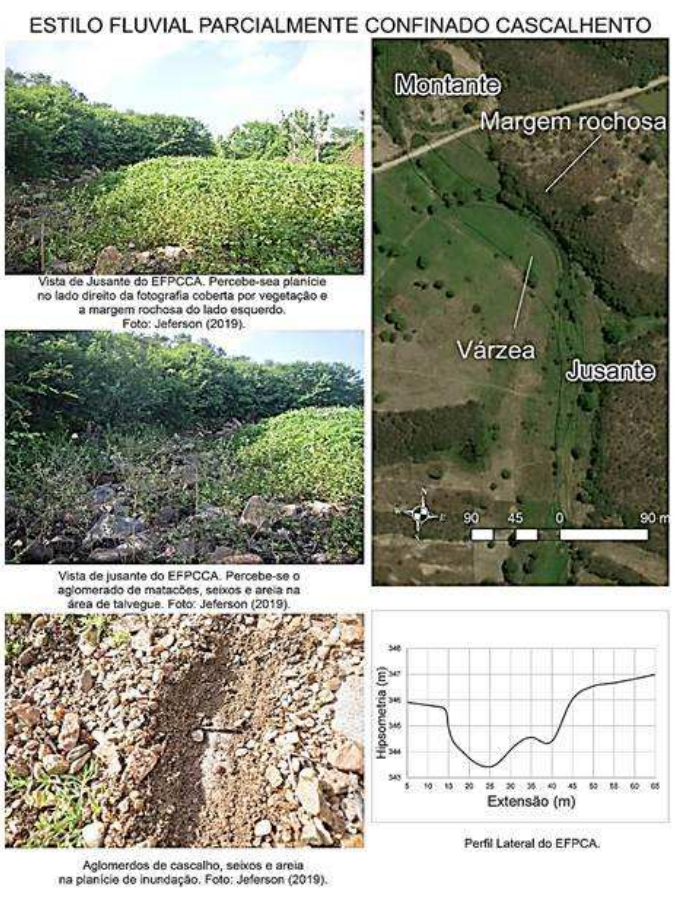

Desta maneira, por mais que esteja situado em uma área majoritariamente aplainada, a dissecação intensa das áreas de cabeceira oferta material sedimentar para o leito fluvial, que 
consegue transportar os finos na estação chuvosa e deixar predominando no ambiente fluvial o material cascalhento. É importante salientar que este estilo drena uma área de $59 \mathrm{~km}^{2} \mathrm{e}$ possui declividade de $0,3 \%$ e corresponde a $13,3 \%$ de toda a extensão do rio Piranhas.

O Estilo Fluvial Parcialmente Confinado Arenoso está localizado na foz no rio do Piranhas e totalmente inserido na unidade de relevo Superfície Pedimentar de Acumulação. Esse estilo fluvial apresenta canal único, com planícies de inundação, barras, ilhas e terraço na margem esquerda (Figura 9). Nessa perspectiva, o fator confinante de uma das margens é a encosta que impede o extravasamento do fluxo na margem esquerda. É importante salientar que o canal é composto por um leito arenoso. Desta maneira, situado em uma unidade de relevo que tem como principal característica a superfície plana, o canal apresenta $0,08 \%$ de declividade e drena uma área de $5809 \mathrm{~km}^{2}$. A questão do caráter fluvial neste estilo é invariável à estação climática, pois tanto no período chuvoso como no período seco amplas faixas de material arenoso se acumulam no leito e formam uma capa arenosa. A diferença é que na estação seca o material arenoso fica exposto à superfície.

FIGURA 9 - ESTILO FLUVIAL PARCIALMENTE CONFINADO ARENOSO

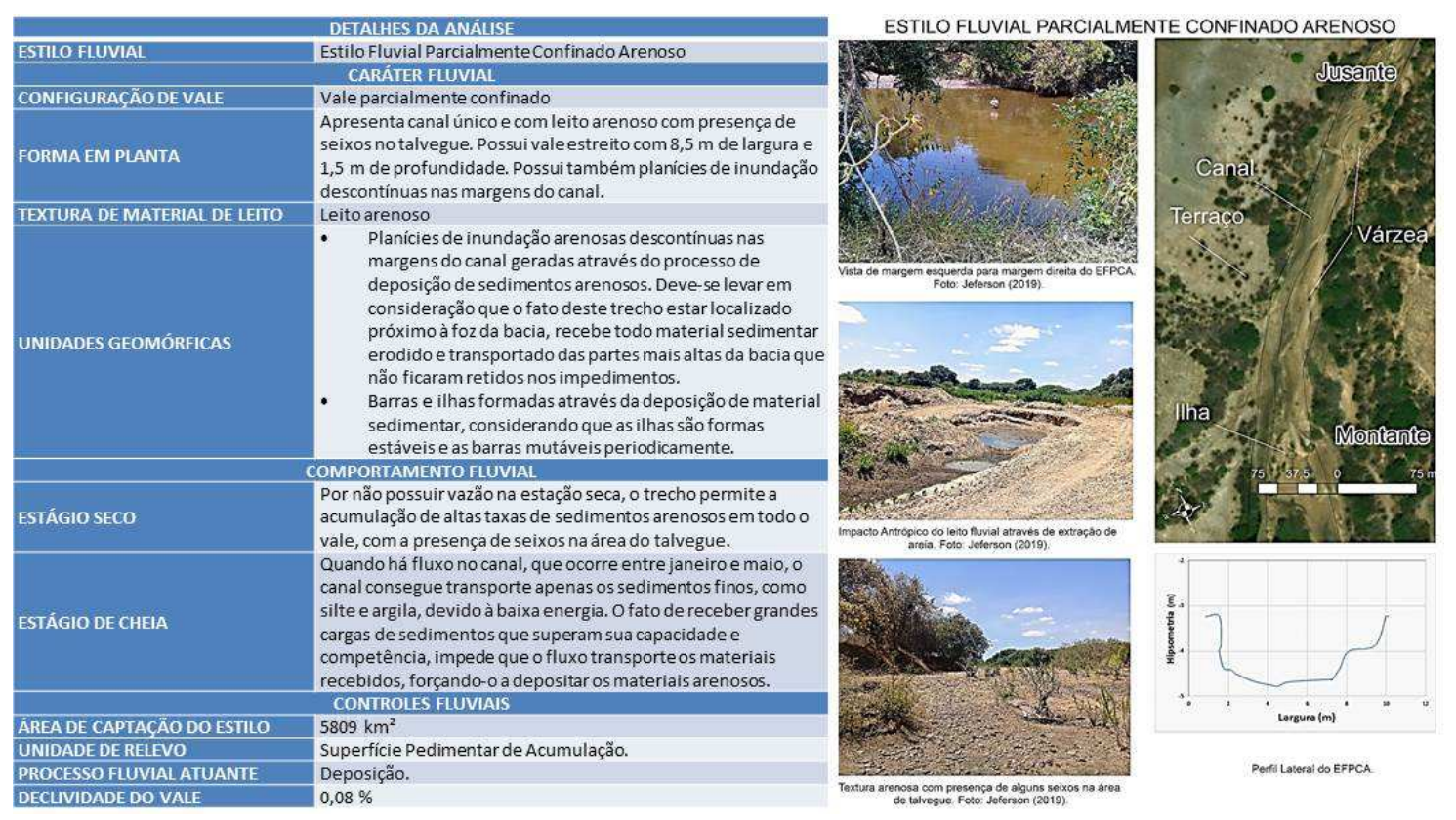

Fonte: Autor, 2020

Os estilos fluviais parcialmente confinados estão situados sobre duas unidades de relevo da bacia hidrográfica do alto curso do rio Piranhas. A característica singular entre eles são as planícies de inundação que ocorrem apenas em uma das margens continuamente. Por 
mais que haja alteração na disposição de inclinação da superfície de acordo com a unidade de relevo em que um trecho de rio está inserido, os estilos fluviais parcialmente confinados do alto Piranhas apresentam baixos valores de declividade. Todavia, de acordo com Brierley e Fryirs (2005), a última instância para determinar um estilo de rio é o material de leito, e este foi o principal fator de diferenciação entre os estilos fluviais parcialmente confinados do alto curso do rio Piranhas.

\section{Estilos não Confinados}

Pensando em trechos de rio não confinados, Brierley e Fryirs (2005) afirmam que podem ser denominados como canais fluviais não confinados àqueles que apresentarem planície de inundação em mais de $90 \%$ em ambas as margens do trecho fluvial. Desta maneira, o fluxo tem probabilidade de extravasamento nos períodos de cheia, por não ter controles nas margens. O Estilo Fluvial Não Confinado Arenoso (EFNCA) é o trecho de maior extensão da bacia hidrográfica, ocupando uma faixa de $37,4 \%$ de toda extensão do alto curso do rio Piranhas. Esse estilo fluvial não possui confinamento nas margens e apresenta planícies de inundação contínuas. Escoa sobre rochas cristalinas do paleoproterozóico e seu vale é largo, com valores que chegam em média a 53,7 m de largura e 2,98 m de profundidade (Figura 10).

\section{FIGURA 10 - ESTILO FLUVIAL NÃO CONFINADO ARENOSO}

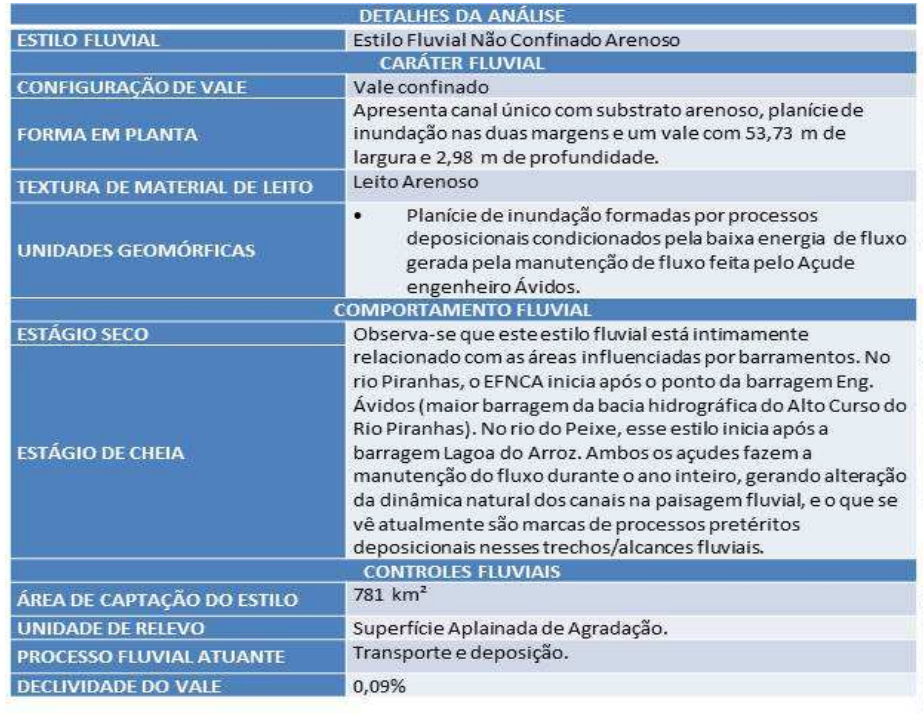
PROCESSO FLUVIAL ATUANTE $0,09 \%$

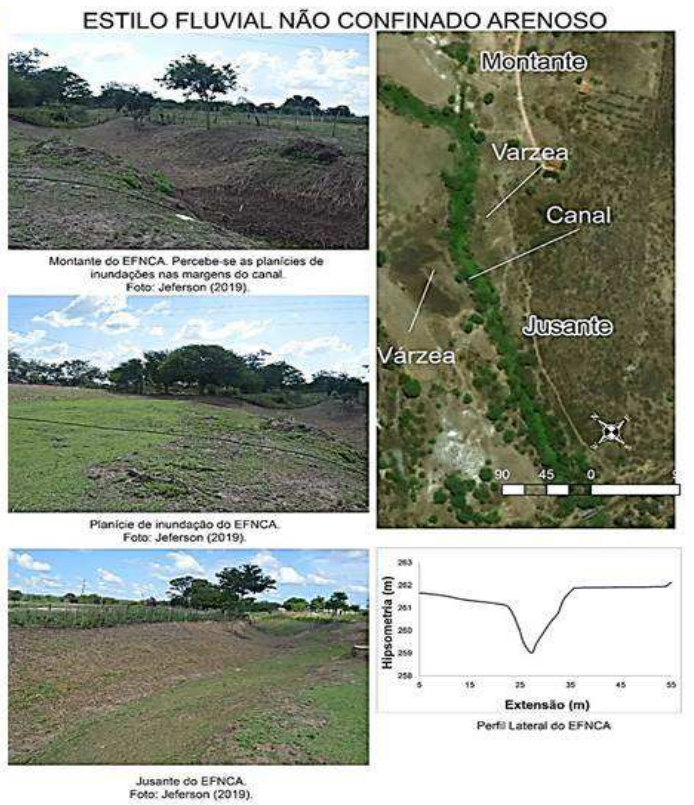

Jusante co EFNCA
Foto: Jeferson (2019)

Fonte: Autor, 2020 
De modo geral, a largura está intimamente relacionada às áreas deposicionais correspondentes às planícies de inundação, enquanto que o talvegue forma um desnível em forma de "V" no ambiente fluvial. Este trecho escoa a baixas declividades, tendo em vista a disposição plana da unidade de relevo em que está inserida, que corresponde à unidade de Pedimentos dissecados, que apresenta característica de relevo ondulado a suave ondulado. Sua área de captação no rio Piranhas é de aproximadamente $781 \mathrm{~km}^{2}$.

O Estilo Fluvial Não Confinado Rochoso e Cascalhento (EFNCRC) está localizado entre o EFNCA e o EFPCA, sobre a Superfície Aplainada de Agradação. Esse estilo apresenta textura cascalhenta no leito, o que permite inferir que possui competência de fluxo capaz de transportar os materiais finos (areia, silte e argila) em sentido de jusante (Figura 11).

\section{FIGURA 11 - ESTILO FLUVIAL NÃO CONFINADO ROCHOSO E CASCALHENTO}

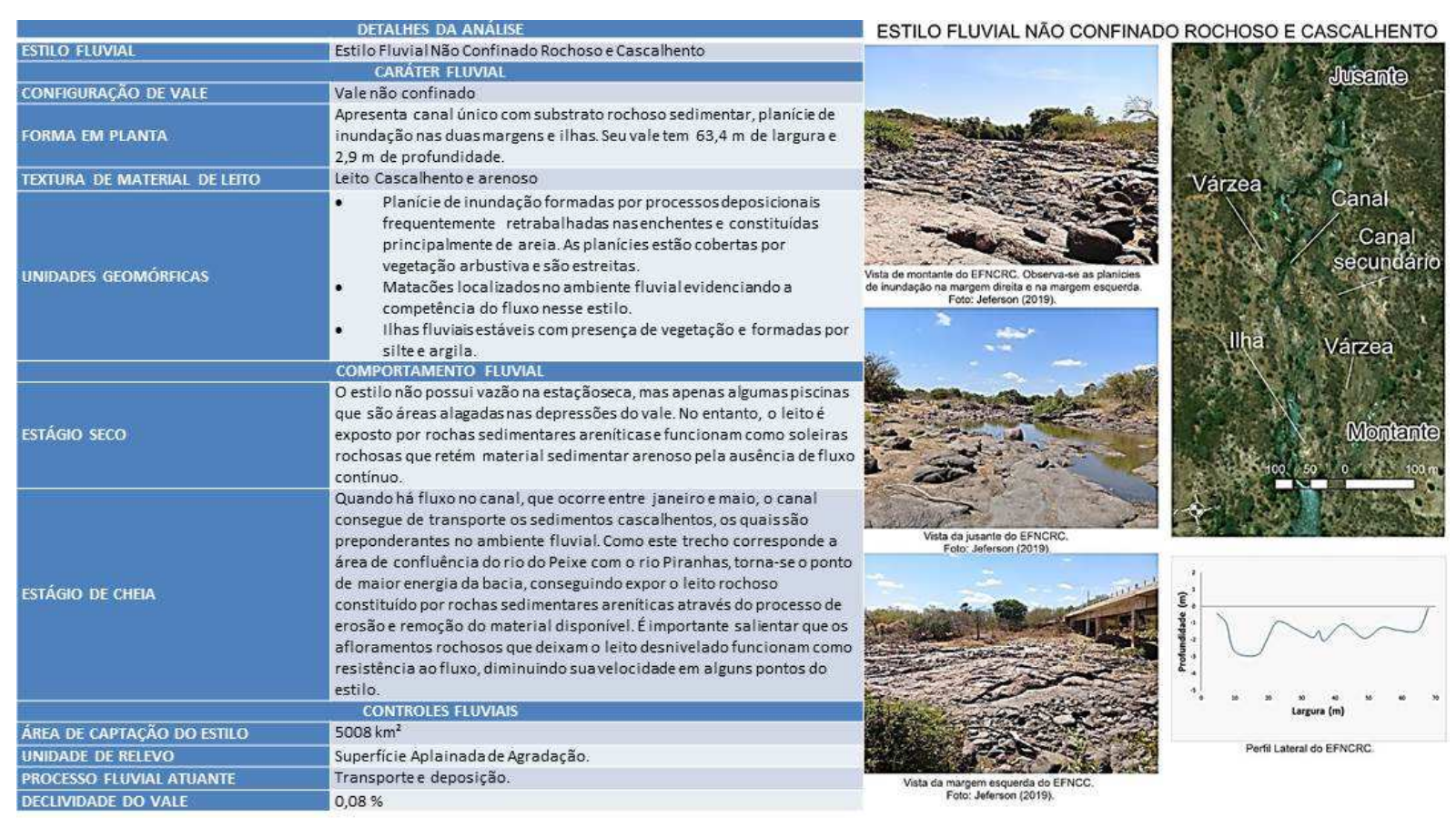

Fonte: Autor, 2020

O EFNCRC apresenta declividade de 0,08 \%, semelhante a do EFNCA, mas seu leito é composto por um substrato rochoso que expõe a unidade geológica Sousa, ou seja, sedimentar, evidenciando capacidade e competência de transporte maior que a do EFNCA, certamente por conta da maior área de captação do EFNCRC que é de cerca de $5000 \mathrm{~km}^{2} \mathrm{e}$ corresponde a $18,2 \%$ de toda a extensão do rio Piranhas. Também é importante salientar que 
este estilo apresenta amplas planícies de inundação que constituem junto com o leito menor um vale fluvial com $63 \mathrm{~m}$ de largura e profundidade de 2,9 m. O leito é assimétrico e a exposição de rocha cristalina controla a evolução vertical do canal, permitindo apenas que as planícies cascalhentas e arenosas sejam retrabalhadas com maior frequência.

De modo geral, estilos fluviais estão intimamente ligados às características de paisagem e relevo de suas bacias, os quais refletem na morfologia e processos fluviais as condições ambientais por onde escoam os rios (BRIERLEY et al, 2019). Também são úteis para definir as zonas processuais que ocorrem na extensão de qualquer segmento fluvial e apontar para possíveis condições ambientais da bacia. Nessa perspectiva, observa-se na bacia do alto curso do rio Piranhas que os estilos fluviais não são homogêneos ou repetitivos durante a extensão do rio Piranhas, considerando que as variações topográficas e geológicas que constituem as unidades de relevo demonstram forte influência na dinâmica e morfologia fluvial do referido canal.

\section{CONSIDERAÇÕES FINAIS}

A estrutura de estilos de rio é mundialmente conhecida e aplicada em diversas áreas que vão de ambientes secos a ambientes úmidos, permitindo sua aplicabilidade sem generalizações e adaptações que permite avaliar a realidade de sistemas fluviais. Essa proposta teórico-metodológica permitiu uma compreensão quali-quantitativa do alto curso do rio Piranhas.

Foram definidos trechos representativos de cada estilo fluvial para o alto curso do rio Piranhas e que partiram da escala de bacia para escala de detalhe de canal, pois a estrutura de estilos de rio permite dissecar efetivamente a bacia hidrográfica (BRIERLEY e FRYIRS, 2005). Nessa perspectiva, as unidades geomórficas foram utilizadas como a variável principal de diferenciação de estilos de rio, enquanto a textura diferenciou canais de confinamento semelhante. A configuração de vale foi o ponto de partida para definição dos estilos fluviais, onde o confinamento do vale define a capacidade do canal em se ajustar no ambiente fluvial, determinando padrões de armazenamento e retrabalho de sedimentos.

O caráter e comportamento fluviais foram evidenciados a partir da compreensão das variáveis de análise da etapa 2 do estágio 1, permitindo identificar a variedade de paisagens fluviais geradas por diferentes formas e processos atuantes na bacia hidrográfica do alto curso do rio Piranhas. Os processos foram intimamente influenciados pelas unidades de relevo, 
onde as características inerentes a cada unidade de relevo geram os controles que permitem o desenvolvimento das formas fluviais e consequentemente sua dinâmica.

Os canais confinados apresentaram predominantemente processos erosivos e indícios de alta competência e capacidade de transporte fluviais, com vales relativamente estreitos. Os canais parcialmente confinados apresentaram processos de erosão e deposição em diferentes pontos do ambiente fluvial, onde na margem confinante o processo erosivo foi predominante, enquanto na planície de inundação observou-se o indício de deposição fluvial. Os vales também são relativamente estreitos, com menos de 10 metros de largura. Por fim, os canais não confinados apresentaram majoritariamente a presença de deposição nas margens fluviais, sendo observadas na forma de amplas planícies de inundação. Os vales são largos, como é evidenciado no EFNCRC que apresentou cerca de 63, $4 \mathrm{~m}$ de largura.

A estrutura de estilos pode ser aplicada a qualquer bacia hidrográfica de qualquer ambiente, considerando que aborda principalmente as questões morfológicas de canais fluviais, além de ser uma estrutura de classificação aberta que permite a inserção de variáveis de análise conforme necessária a cada pesquisa.

\section{REFERÊNCIAS}

BRIERLEY, G; FRYIRS, K. Geomorphology and River Management: applications of the river styles framework. Oxford: Blackwell Publishing, 2005. 412 p.

BRIERLEY, G; FRYIRS, K; MARÇAL, M; LIMA, R. THE USE OF THE RIVER STYLES FRAMEWORK AS A TOOL TO 'WORK WITH NATURE' IN MANAGING RIVERS IN BRAZIL: examples from the Macaé catchment. Revista Brasileira de Geomorfologia, [S.L.], v. 20, n. 4, p. 751-771, 1 out. 2019.

DATRY, T.; BOULTON, J.; BONADA, N.; FRITZ, K.; LEIGH, C.; SAUQUET, E.; TOCKNER, K.; HUGUENY, B.; DAHM, N. Flow intermittence and ecosystem services in rivers of the Anthropocene. Journal Of Applied Ecology, [S.L.], v. 55, n. 1, p. 353-364, 26 jun. 2017.

GONÇALVES, L. Estudo Magnético e Gravimétrico do Arcabouço Estrutural da Bacia Rio do Peixe -. Estudo Magnético e Gravimétrico do Arcabouço Estrutural da Bacia Rio do Peixe - PB. 2009. 114 f. Dissertação (Mestrado) - Curso de Geologia, Universidade de Brasília, Brasília, 2009.

GRAFF, W. L. Arid Zone Geomorphology: Process, Form and Change in Drylands. Oxford, Uk: John Wiley \& Sons, Ltd, 2011.

KOUSKY, V. E.; GAN, M. A. Upper tropospheric cyclonic vortices in the tropical South Atlantic. Tellus, Copenhagen, n. 33, p.538-551, 1981. 
MAIA, R. S. Identificação e caracterização dos estilos fluviais da Bacia do Riacho do tigre - PB. 2016. 82 f. Monografia (Especialização) - Curso de Geografia, Universidade Federal da Paraíba, João Pessoa, 2016.

MAIA, R; BEZERRA, F. NEOTECTÔNICA, GEOMORFOLOGIA E SISTEMAS FLUVIAIS: UMA ANÁLISE PRELIMINAR DO CONTEXTO NORDESTINO. Revista Brasileira de Geomorfologia, Uberlândia, v. 12, n. 3, p.37-46, 2010.

NOGUEIRA, F; OLIVEIRA, M; CASTRO, D. Estudo Magnético e Gravimétrico do Arcabouço Estrutural da Bacia Rio do Peixe - PB. Revista de Geologia, S.L, v. 1, n. 17, p. 74-87, jan. 2004.

OLIVEIRA, H. C. IMPACTOS HIDROFÍSICOS NA BACIA HIDROGRÁFICA DO ALTO CURSO DO RIO PARAÍBA FRENTE A SUA PERENIZAÇÃO. 2018. $104 \mathrm{f}$. Monografia (Especialização) - Curso de Geografia, Universidade Federal da Paraíba, João Pessoa, 2018.

ROSGEN, D. A classification of natural rivers. Catena, [s. L.], v. 22, n. 3, p.169-199, jun. 1994.

RODRIGUES, J. ESPACIALIZAÇÃO DAS CHUVAS EM UMA BACIA HIDROGRÁFICA NO SEMIÁRIDO DA PARAÍBA. Revista de Geociências do Nordeste, [S.L.], v. 6, n. 1, p. 28-35, 16 maio 2020.

SANTOS, A. H. L. ANÁliSE dOS ESTILOS FLUVIAIS E DA CAPACIDADE DE AJUSTE DO ALTO CURSO DO RIO PARAÍBA - PB. 2017. 89 f. Monografia (Especialização) - Curso de Geografia, Universidade Federal da Paraíba, João Pessoa, 2017.

SILVA, R et al. Uso do índice RDE para determinação de anomalias de drenagem no Rio Capibaribe (PE). Reget, Santa Maria, v. 20, n. 1, p.552-565, abr. 2016.

SOUZA, J. O. P. Modelos de evolução da dinâmica fluvial em ambiente semiárido - bacia do Riacho do Saco, Serra Talhada, Pernambuco. 2014. 191 f. Tese (Doutorado) - Curso de Geografia, Universidade Federal de Pernambuco, Recife, 2014.

SUTFIN, N. A. et al. A geomorphic classification of ephemeral channels in a mountainous, arid region, southwestern Arizon. Geomorphology, [s. L.], v. 221, p.164-175, set. 2014.

TOOTH, S. Process, Form and change in dryland rivers: a review of recente research. EarthScience Reviews, v. 51, p. 67 - 107. 2000.

VAREJÃO-SILVA, M. A. Meteorologia e Climatologia. 2. ed. Recife: Versão Digital, 2006. $463 \mathrm{p}$.

WOHL, E.; MERRITT, D. Bedrock channel morphology. Geological Society Of America Bulletin, [S.L.], v. 113, n. 9, p. 1205-1212, set. 2001. 